\title{
Investigation of Photocatalytic Degradation of Methyl Orange by Using Nano-Sized ZnO Catalysts
}

\author{
Changchun Chen ${ }^{1 *}$, Jiangfeng Liu ${ }^{1}$, Ping Liu ${ }^{2}$, Benhai $\mathbf{Y u}^{1}$ \\ ${ }^{1}$ College of Physics and Electronics Engineering, XinYang Normal University, XinYang, China \\ ${ }^{2}$ College of Materials Science and Engineering, Nanjing University of Technology, Nanjing, China \\ E-mail: changchunchen@hotmail.com \\ Received December 30, 2010; revised January 19, 2011; accepted January 22, 2011
}

\begin{abstract}
Nano-sized ZnO catalysts were prepared by a direct precipitation method under the optimal conditions (calcination of precursors at $550^{\circ} \mathrm{C}$ for $120 \mathrm{~min}$ ). The as-synthesized $\mathrm{ZnO}$ catalysts were characterized by X-ray diffraction (XRD), scanning electron microscope (SEM) and UV-Vis spectroscopy. The photocatalytic properties of $\mathrm{ZnO}$ nanoparticles were investigated via methyl orange (MO) as a model organic compound under UV light irradiation. The influence of operating parameters on $\mathrm{MO}$ degradation including the amount of $\mathrm{ZnO}$ catalysts, $\mathrm{pH}$ value of solutions, and the photodegradation temperature was thoroughly examined. In addition, the kinetic process of photocatalytic degradation of $\mathrm{MO}$ using nano-sized $\mathrm{ZnO}$ catalyst was also examined, and the degradation of MO follow the first order kinetics.
\end{abstract}

Keywords: ZnO Nanoparticles, Photocatalytic Degradtion, Methyl Orange

\section{Introduction}

Semiconductor photocatalysts such as $\mathrm{TiO}_{2}$ and $\mathrm{ZnO}$ nano-particles have attracted much attention in recent years due to their various applications to the photocatalytic degradation of organic pollutants in water and air and dye sensitized photovoltaic solar cell [1-3]. Among these semiconductor photocatalysts, $\mathrm{TiO}_{2}$ is the most commonly used owing to its stable, harmless and inexpensive properties. However, two typical defects including only exciting by high energy UV irradiation and a low quantum yield rate resulted from a low rate of electron transfer to oxygen and a high rate of recombination between excited electron/hole pairs, limit the photooxidation rate of $\mathrm{TiO}_{2}$ nanoparticles. In order to improve the photocatalytic efficiency of $\mathrm{TiO}_{2}$ nanoparticles, most studies have been focused on the modification of $\mathrm{TiO}_{2}$ doped by metal ions, especially transition metal ions, which make it possible for $\mathrm{TiO}_{2}$ to absorb visible light by increasing the charge separation [4,5]. In addition, combination of different kinds of semiconductor photocatalysts also is a promising way to improve the photocatalytic efficiency [6]. Recently, $\mathrm{ZnO}$ nanoparticles appear to be a suitable alternative to $\mathrm{TiO}_{2}$ nanoparticles used for the photodegradation of pesticide carbetamide [7], herbicide triclopyr [8], pulp milling bleaching wasterwater [9], 2-phenylphenol [10], phenol [11], reactive blue 19 [12], and acid red 14 [13]. The substitution of $\mathrm{TiO}_{2}$ by $\mathrm{ZnO}$ used for photo-degradation is ascribed to the photo-degradation mechanism of $\mathrm{ZnO}$ being similar to that of $\mathrm{TiO} 2[3,14]$. K. Gouvea et al. has confirmed that $\mathrm{ZnO}$ exhibits a better efficiency than $\mathrm{TiO}_{2}$ in photocatalytic degradation of some reactive dyes in aqueous solution [15]. As we known, $\mathrm{ZnO}$ nanoparticles can be synthesized by various approaches including sol-gel processing, homogeneous precipitation, mechanical milling, organometallic synthesis, microwave method, spray pyrolysis, thermal evaporation and mechanochemical synthesis. However, $\mathrm{ZnO}$ nanoparticles fabricated by the abovementioned methods are prone to aggregate due to the large surface area and high surface energy. In order to improve the dispersion, it is necessary to modify the surface of $\mathrm{ZnO}$ nanoparticles. Some researches have revealed several physical and chemical methods for modifying the surface of $\mathrm{ZnO}$ nanoparticles. The chemical surface modification, which can be classified as surface grafting and esterification, is the most promising method because of the strong covalent bond between the surface modified particles and polymer chains. In previous researches, the $\mathrm{ZnO}$ nanoparticles were ever modified by $\mathrm{SiO}_{2}$ [16], PMMA [17] and PSt [18], and the influence of particles on the mechanical properties of polymer matrix 
was studied.

In the present article, the nano-sized $\mathrm{ZnO}$ catalysts were prepared by a direct precipitation method under the optimal conditions (calcination of precursors at $550^{\circ} \mathrm{C}$ for $120 \mathrm{~min}$ ). The surfaces of $\mathrm{ZnO}$ nanoparticles fabricated by a direct precipitation method are not modified by $\mathrm{SiO}_{2}, \mathrm{PMMA}$ and PSt. The effect of various experiment parameters such as the amount of $\mathrm{ZnO}$ catalyst, $\mathrm{pH}$ of solutions, the photodegradation temperature, and the initial concentration of $\mathrm{MO}$ on the degradation of the MO has been thoroughly examined with an aim to quantitatively probing the regulation of photocatalytic activity of $\mathrm{ZnO}$ nano-sized particles fabricated by a direct precipitation method.

\section{Experimental}

\subsection{Preparation and Characterization}

Nano-sized ZnO particles in this study were prepared by a direct precipitation method. $\mathrm{Zn}\left(\mathrm{NO}_{3}\right)_{2},\left(\mathrm{NH}_{4}\right)_{2} \mathrm{CO}_{3}$, ethanol and de-ionized water were used in the experiments. All the reagents used in this study were the analytical grade. The synthetic procedures of nano-sized $\mathrm{ZnO}$ particles were also thoroughly introduced elsewhere [19]. As is reported in our recent study [20], the nanosized $\mathrm{ZnO}$ particles fabricated by a direct precipitation method via the calcination of precursors at $550^{\circ} \mathrm{C}$ for $120 \mathrm{~min}$ have the optimal photocatalytic activity. As a result, the nano-sized $\mathrm{ZnO}$ particles synthesized by the calcination of precursor at $550^{\circ} \mathrm{C}$ for 120 min were used as catalysts in this study. The specific surface area of nano-sized $\mathrm{ZnO}$ particles synthesized by the calcination of precursor at $550^{\circ} \mathrm{C}$ for 120 min was determined by nitrogen absorption Brunauer-Emett-Teller (BET) method. The BET measurements were performed on a Micromeritics ASAP 200 instrument. The $26.58 \mathrm{~m}^{2} / \mathrm{g}$ of BET specific surface area was obtained. The structural properties of these nano-sized $\mathrm{ZnO}$ particles were investigated by the $\theta-2 \theta$ method of X-ray diffraction (XRD) with a $\mathrm{Cu}$ $\mathrm{K}_{\alpha 1}(\lambda=0.154 \mathrm{~nm})$ radiation at $40 \mathrm{kV}$ and $30 \mathrm{~mA}$ using a multipurpose XRD system (PANalytical). The morphology and particle size of these nano-sized $\mathrm{ZnO}$ particles were also analyzed by a scanning electron microscope (SEM, JXA840). SEM photographs for the nano-sized $\mathrm{ZnO}$ particles were recorded (LEO 435) at $30 \mathrm{kV}$ from samples covered with a thin gold film.

\subsection{Photocatalytic Degradation}

The MO solutions in concentrations varied from 5 to 50 $\mathrm{mg} / \mathrm{L}$ (5, 10, 20, 30, 40 and 50) were prepared through dissolving MO powders in ultra pure water, respectively. The concentration of MO solution was determined by measuring the value at approximately $464 \mathrm{~nm}$ using a
UV-Vis spectrophotometer 756PC (China). The reaction suspensions were prepared by adding nano-sized $\mathrm{ZnO}$ particles into the abovementioned MO solutions. The suspensions were ultrasonically sonicated for $20 \mathrm{~min}$ and magnetically stirred in dark for 45 min to ensure an adsorption/desorption equilibrium. The reaction suspensions containing $\mathrm{MO}$ and nano-sized $\mathrm{ZnO}$ photocatalyst were irradiated by a $300 \mathrm{~W}$ high-pressure mercury lamp with continuous stirring. In addition, the $\mathrm{pH}$ of $\mathrm{MO}$ solution adjusted by adding $\mathrm{NaOH}$ or $\mathrm{HCl}$ solutions was measured using Elico LI120. Absorbance measurements were also recorded in the range of 200-600 nm, using a UV-vis spectrophotometer. The photocatalytic degradation efficiency of the MO solutions was calculated with the following formula: $\eta=\frac{A_{0}-A}{A_{0}} \times 100 \%$, where $A_{0}$ is the absorbance of $\mathrm{MO}$ dye solution before the illumination, $A$ is the absorbance of MO solutions in suspension after time $t$.

\section{Results and Discussion}

The XRD pattern of $\mathrm{ZnO}$ nanoparticles synthesized via the calcination of precursor at $550^{\circ} \mathrm{C}$ for $120 \mathrm{~min}$ is showed in Figure 1. It could be seen that the diffraction peaks were more intensive and narrower implying a good crystalline nature of the as-synthesized $\mathrm{ZnO}$ product, and all of the peaks can be well indexed to hexagonal phase $\mathrm{ZnO}$ reported in JCPDS card (NO.36-1451, a = 0.3249 nm, $\mathrm{c}=0.5206 \mathrm{~nm}$ ). Diffraction peaks related to the impurities were not observed in the XRD pattern, confirming the high purity of the synthesized product. The average crystalline size $(L)$ of the nano-sized $\mathrm{ZnO}$ particles can be calculated from the Debye-Scherrer formula [21]:

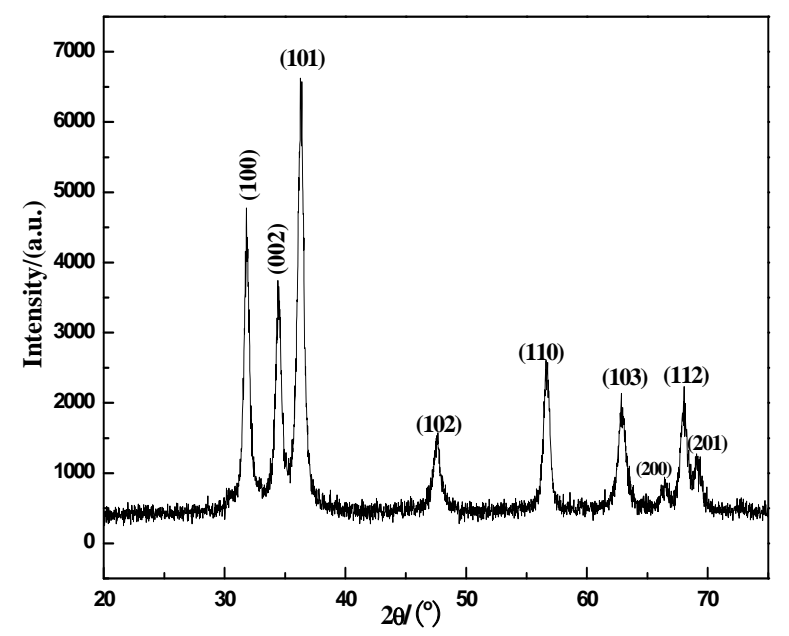

Figure 1. XRD patterns of nano-sized $\mathrm{ZnO}$ particles synthesized by a direct precipitation method with the calcination of precursor at $550^{\circ} \mathrm{C}$ for 120 minutes. 
$L=\frac{0.89 \lambda}{\beta \cos \theta}$, where $L$ is the crystalline size (in $\mathrm{nm}$ ), $\lambda$ is the wavelength (in $\mathrm{nm}$ ), $\beta$ is the full width at half maximum intensity (FWHM--in radian), and $\theta$ is the Bragg diffraction angle $\left({ }^{\circ}\right)$. The average crystalline size of $\mathrm{ZnO}$ product synthesized was figured out from the Debye-Scherrer formula to be about $17.3 \mathrm{~nm}$. Typical SEM image of the $\mathrm{ZnO}$ nano-particles calcinated at $550^{\circ} \mathrm{C}$ for 120 min is shown in Figure 2. The $\mathrm{ZnO}$ nanoparticles are reasonably uniform in size, and the morphology of the $\mathrm{ZnO}$ nano-particles takes on pseudo-spherical shape. The average size of the $\mathrm{ZnO}$ nanoparticles is approximately $20 \mathrm{~nm}$, which is consistent with the crystallite size estimated from the XRD analysis shown in Figure 1.

The photocatalytic activity of $\mathrm{ZnO}$ nanoparticles was assessed according to the photo-degradation kinetics of $\mathrm{MO}$ solutions. The dependence of the amount of $\mathrm{ZnO}$ nanoparticles on the photodegradation efficiency of $1 l$ MO solutions with an initial concentration of $10 \mathrm{mg} / \mathrm{l}$ at the neutral $\mathrm{pH}$ value was shown in Figure 3. Experiments show that the photo-degradation efficiency of MO solution increases with the increase of amount of $\mathrm{ZnO}$ photocatalysts, after which it reaches the highest value of catalyst amount $(2.5 \mathrm{~g} / \mathrm{l})$, and then decrease. This observation can be explained in terms of availability of active sites on the surface of catalyst and the penetration of UV light into the suspension [22]. The total active surface area of $\mathrm{ZnO}$ nano-particles increases with the increase of catalyst dosage. On the other hand, with an increase in the turbidity of the MO suspension, the penetration of UV light will decrease as a result of the increased scattering effect.

The effect of $\mathrm{pH}$ in the range of $\mathrm{pH} 3.0-11.0$ on the photo-catalytic degradation rate of MO was investigated. The photodegradation efficiency of $1 \mathrm{l} \mathrm{MO}$ solution with an initial concentration of $10 \mathrm{mg} / \mathrm{l}(\mathrm{ZnO}$ concentration = $2.5 \mathrm{~g} / \mathrm{l})$ as a function of $\mathrm{pH}$ of $\mathrm{MO}$ solutions were shown in Figure 4. The strong effect of $\mathrm{pH}$ on the photodegradation efficiency of MO solution was observed. The highest removal rate of $\mathrm{MO}$ was obtained at a $\mathrm{pH}$ of 7.0.

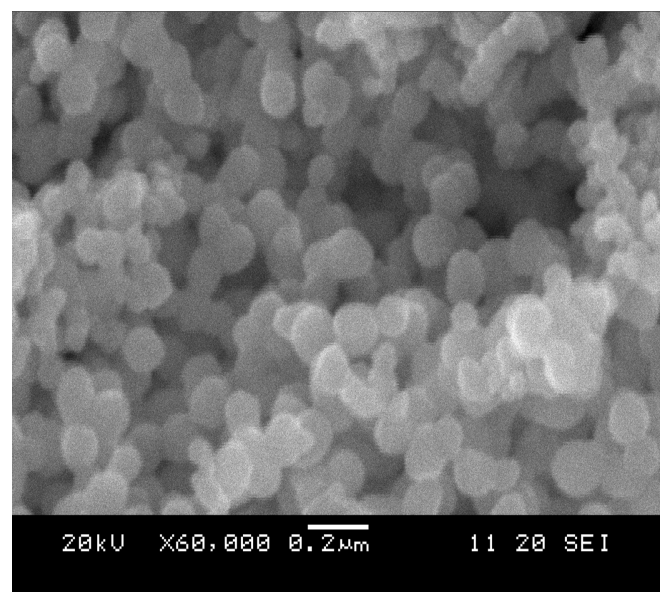

Figure 2. The SEM image of nano-sized $\mathrm{ZnO}$ particles synthesized by a direct precipitation method with the calcination of precursor at $550^{\circ} \mathrm{C}$ for 120 minutes.

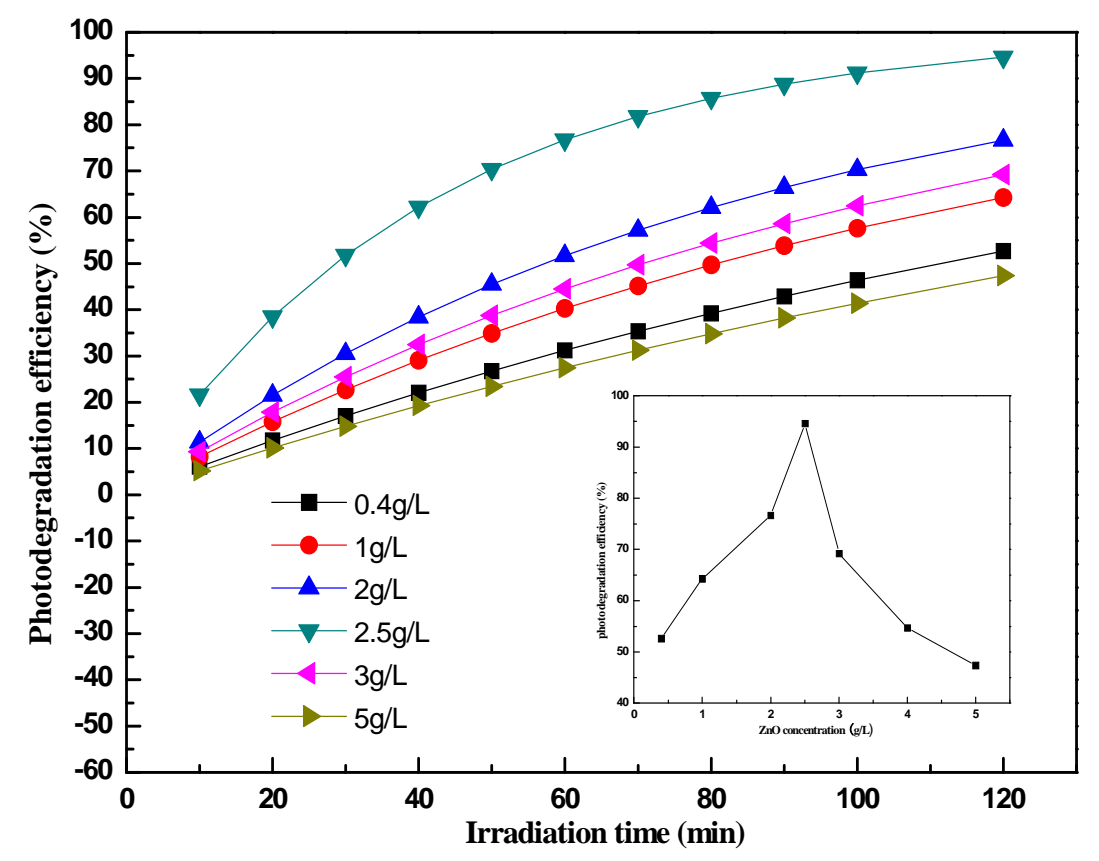

Figure 3. The effect of $\mathrm{ZnO}$ amount on the photodegradation efficiency of MO solutions. 


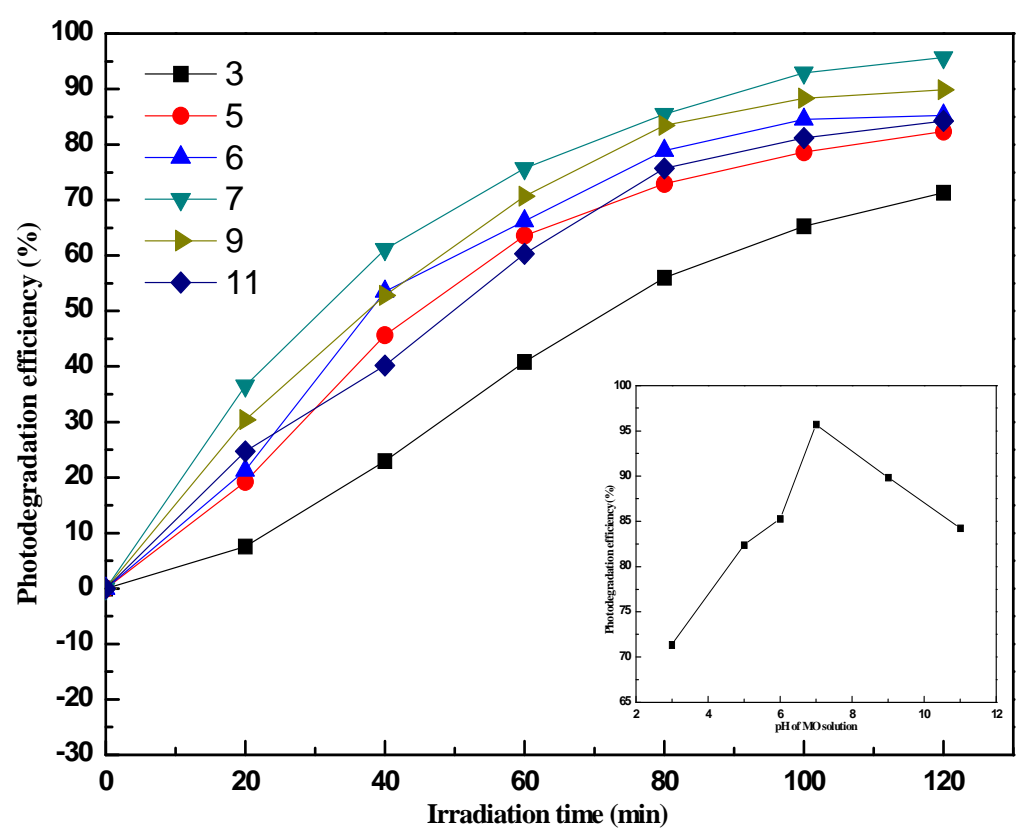

Figure 4. Effect of pH on the photodegradation efficiency of methyl orange at different irradiation times.

However, when $\mathrm{TiO}_{2}$ nanoparticles were utilized to catalyze the photo-degradation of MO, the higher removal rate of $\mathrm{MO}$ was obtained at lower $\mathrm{pH}$ values, which is reported in literature [23]. The effect of $\mathrm{pH}$ on the photodegradation of $\mathrm{MO}$ using $\mathrm{ZnO}$ catalysts can be explained as follows. As is pointed out by E. Topoglidis et al. [24], the point of zero charge (PZC) of nano-sized $\mathrm{ZnO}$ particle is about a $\mathrm{pH}$ of 9.30. Above the $\mathrm{pH}$ value, the surfaces of nano-sized $\mathrm{ZnO}$ particles are negatively charge. Below the $\mathrm{pH}$ value, the surfaces of nano-sized $\mathrm{ZnO}$ particles are positively charged. Methyl orange molecules have negative charges in a wide $\mathrm{pH}$ value range. Therefore, when the MO solution $\mathrm{pH}$ value is below the PZC, the MO anions should be readily adsorbed on the surfaces of nano-sized $\mathrm{ZnO}$ particles.

As is described by $\mathrm{H}$. Tian et al. [1], the photocatalytic degradation efficiency of MO solutions with nano-sized $\mathrm{TiO}_{2}$ catalysts changes with the temperature variation of the MO solutions. Hence, the effect of MO solution temperature on the degradation efficiency of MO catalyzed by $\mathrm{ZnO}$ nano-particles was also discussed in the range from 20 to $70^{\circ} \mathrm{C}$ at $10^{\circ} \mathrm{C}$ intervals in this study. It can be seen in Figure 5 that at the first stage, the photo-degradation ratios of $\mathrm{MO}$ ascend with the increase of solution temperature from $20^{\circ} \mathrm{C}$ to $50^{\circ} \mathrm{C}$, and begin to decrease at a temperature beyond $50^{\circ} \mathrm{C}$. However, in many cases, the higher the temperature is, the quicker the chemical reaction rate does. The experimental results shown in Figure 5 can be explained as follows. At an elevated temperature, the adsorbability of nano-sized $\mathrm{ZnO}$ particles to $\mathrm{MO}$ becomes low. The lower adsorbability

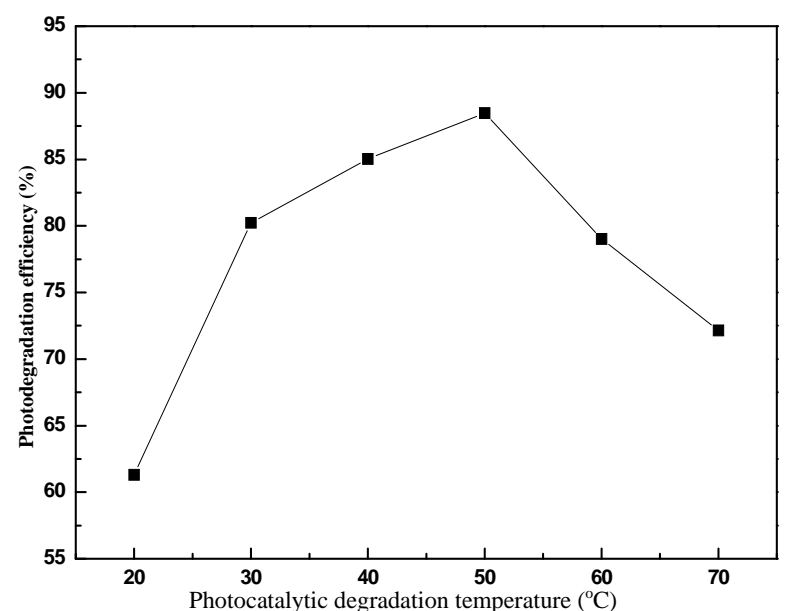

Figure 5. Influence of solution temperature on photodegradation efficiency of methyl orange( MO initial concentration of $10 \mathrm{mg} / \mathrm{l}, \mathrm{ZnO}$ amount of $2.5 \mathrm{~g} / \mathrm{l}$, solution acidity of pH 7.0 and total volume of 11 .

of MO will weaken the direct hole oxidation on the surface of nano-sized $\mathrm{ZnO}$ catalysts.

The photocatalytic decomposition of MO organic pollutants on the surface of $\mathrm{ZnO}$ nano-particles also follow a pseudo first-order kinetic law, and can be expressed as $-\ln \left(\frac{C}{C_{0}}\right)=k t$, where $C$ and $C_{0}$ are the reactant concentration at time $t=t$ and $t=0$, respectively, $k$ and $t$ are the pseudo-first-order rate constant (reaction rate constant) and time, respectively [25]. The relationships between $-\ln \left(C / C_{0}\right)$ and irradiation time (Reaction time) are 
shown in Figure 6. It is obvious that there exists a linear relationship between $-\ln \left(C / C_{0}\right)$ and irradiation time. The pseudo-first-order rate constant $k$ and linear regression coefficient $(R)$ for MO solutions with different initial MO concentrations are summarized in Table 1, respectively.

According to the Langmuir-Hinshelwood model, the fact that the decrease of reaction rate constant with the increase of the initial concentration of MO solutions obtained from Table 1 could be explained as follows. The organic $\mathrm{MO}$ is firstly adsorbed on the surface of nano-sized $\mathrm{ZnO}$ particles, and then the photocatalytic decomposition takes place under UV irradiation. With the increase of the initial MO concentrations, the MO molecules congregate on the surface of nano-sized $\mathrm{ZnO}$ catalysts. However, quenching between these excited MO molecules irradiated by UV will take place [26]. The quenching probability could also increase with the increase of the initial MO concentrations. Consequently, the photocatalytic efficiecncy of MO solutions is decreased with the increase of the initial MO concentrations.

\section{Conclusions}

The nano-sized $\mathrm{ZnO}$ catalysts were prepared via the

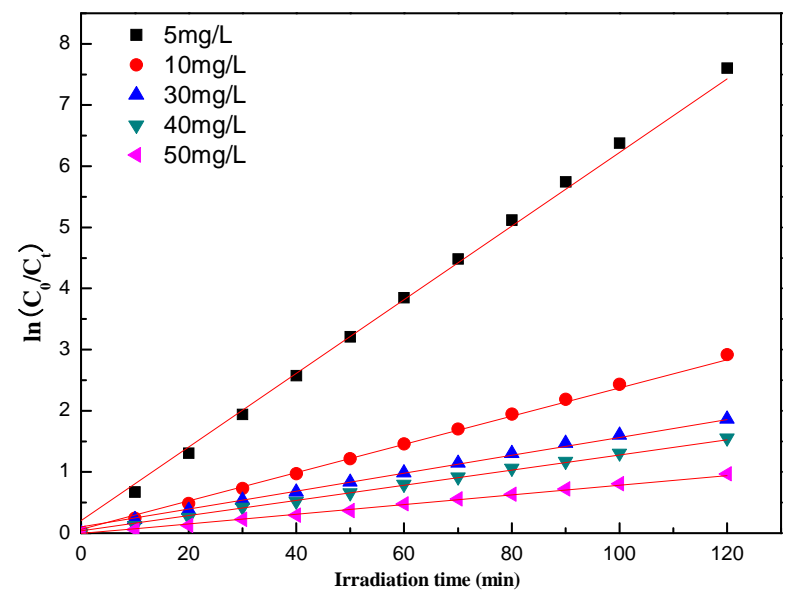

Figure 6. Kinetics of the methyl orange degradation catalyzed by ZnO nanoparticles.

Table 1. Reaction rate constant of MO photocatalytic decomposition with different initial concentration.

\begin{tabular}{ccccc}
\hline Experiments & $\begin{array}{c}\text { ZnO } \\
\text { concentration } \\
(\mathrm{g} / L)\end{array}$ & $\begin{array}{c}\text { Initial } \\
\text { concentration } \\
\text { of MO } \\
\text { solutions } \\
(\mathrm{mg} / L)\end{array}$ & $\begin{array}{c}k \\
\text { (constant) }\end{array}$ & $R^{2}$ \\
\hline 1 & 2.5 & 5 & 0.063812 & 0.9999 \\
2 & 2.5 & 10 & 0.024304 & 0.9999 \\
3 & 2.5 & 30 & 0.016148 & 0.9975 \\
4 & 2.5 & 40 & 0.013099 & 0.9997 \\
5 & 2.5 & 50 & 0.007942 & 0.9982 \\
\hline
\end{tabular}

calcination of precursors at $550^{\circ} \mathrm{C}$ for $120 \mathrm{~min}$. A series of experiments were carried out to study the effects of the amount of photocatalyst, a pH value of MO solutions, and reaction temperature on the photocatalytic degradation efficiency of MO solutions. The photodegradation efficiency increases with the increase in the amount of $\mathrm{ZnO}$ photocatalyst. Once the amount of $\mathrm{ZnO}$ photocatalyst is beyond the highest value of catalyst amount ( $2.5 \mathrm{~g}$. $I^{-1}$ ), the photo-degradation efficiency of MO solution begin to decrease. The photocatalyst capacity of $\mathrm{ZnO}$ towards the methyl orange solutions strongly depends on the $\mathrm{pH}$ of $\mathrm{MO}$ solutions, and the MO solutions catalyzed by $\mathrm{ZnO}$ nano-particles has good photodegradation efficiency at a central $\mathrm{pH}$ value. The photodegradation ratios of MO solutions ascend with the increase of the MO solution temperature from 20 to $50^{\circ} \mathrm{C}$, and they begin to decrease at temperature beyond $50^{\circ} \mathrm{C}$.

\section{Acknowledgements}

This research was partially supported by the Planned Science and Technology Project of Henan Province, China, under Grant No. 082300410050.

\section{References}

[1] H. Tian, J. F. Ma, K. Li and J. J. Li, "Photocatalytic Degradation of Methyl Orange with W-doped $\mathrm{TiO}_{2}$ Synthesized by a Hydrothermal Method," Materials Chemistry and Physics, Vol. 112, 2008, pp. 47-51. doi:10.1016/j.matchemphys.2008.05.005

[2] N. Daneshvar, D. Salari and A. R. Khataee, "Photocatalytic Degration of Azo Dye Acid Red 14 in Water on $\mathrm{ZnO}$ as an Alternative Catalyst to $\mathrm{TiO}_{2}$," Journal of Photochemistry and Photobiology A: Chemistry, Vol. 162, 2004, pp. 317-322. doi:10.1016/S1010-6030(03)00378-2

[3] L. Andronic and A. Duta, "The Influence of $\mathrm{TiO}_{2}$ Powder and Film on the Photodegradation of Methyl Orange," Materials Chemistry and Physics, Vol. 112, 2008, pp. 1078-1082. doi:10.1016/j.matchemphys.2008.06.059

[4] Y. Sakata, T. Yamamoto, T. Okazaki, H. Imamura and S. Tsuchiya, "Generation of Visible Light Response on the Photocatalyst of a Copper Ion Containing $\mathrm{TiO}_{2}$," Chemistry Letters, Vol. 27, 1998, pp. 1253-1257. doi:10.1246/cl.1998.1253

[5] M. Iwasaki, M. Hara, H. Kawada, H. Tada and S. Ito, "Cobalt Ion-Doped $\mathrm{TiO}_{2}$ Photocatalyst Response to Visible Light,” Journal of Colloid and Interface Science, Vol. 224, 2000, pp. 202-207. doi:10.1006/jcis.1999.6694

[6] H. Tian, J. F. Ma, X. Huang, L. J. Xie, Z. Q. Zhao, J. Zhou, P. W. Wu, J. H. Dai, Y. M. Hu, Z. B. Zhu, H. F. Wang and H. Y. Chen, "Nano-Sized Coupled Photocatalyst $\left(\mathrm{Sn}_{0.25} \mathrm{Ti}_{0.75}\right) \mathrm{O}_{2}$ Powders Synthesized by a Low Temperature Molten Salt Method," Materials Letters, Vol. 59, 2005, pp. 3059-3061. doi:10.1016/j.matlet.2005.05.020 
[7] I. Poulios, M. Kositzi and A. Kouras, "Photocatalytic Decomposition of Trichlopyr over Aqueous Semiconductor Suspensions," Journal of Photochemistry and Photobiology A: Chemistry, Vol. 115, 1998, pp. 175-179. doi:10.1016/S1010-6030(98)00259-7

[8] J. P. Percherancier, R. Chapelion and B. Pouyet, "Semiconductor Sensitized Photodegradation of Pestcides in Water: The Case of Carbetamide," Journal of Photochemistry and Photobiology A: Chemistry, Vol. 87, 1995, pp. 261-265. doi:10.1016/1010-6030(94)03993-5

[9] M. C. Yeber, J. Rodriguez, J. Freer, J. Baeza, N. Duran and H. D. Mansilla, "Advanced Oxidation of a Pulp Mill Bleaching Wastewater,” Chemosphere, Vol. 39, 1999, pp. 1679-1683. doi:10.1016/S0045-6535(99)00068-5

[10] A. A. Khodja, T. Sehili, J. F. Pilichowski and P. Boule, "Photocatalytic Degradation of 2-phenylphenol on $\mathrm{TiO}_{2}$ and $\mathrm{ZnO}$ in Aqueous Suspensions," Journal of Photochemistry and Photobiology A: Chemistry, Vol. 141, 2001, pp. 231-236. doi:10.1016/S1010-6030(01)00423-3

[11] C. Marci, V. Augugliaro, M. J. L. Munoz, C. Martin, L. Palmisano, V. Rives, M. Sehhiavello, R. J. D. Tilley and A. M. Venezia, "Preparation Characterization and Photocatalytic Activity of Polycrystalline $\mathrm{ZnO} / \mathrm{TiO}_{2}$ Systems," The Journal of Physical Chemistry B, Vol. 105, No. 5, 2001, pp. 1026-1032. doi:10.1021/jp003172r

[12] C. Lizama, J. Freer, J. Baeza and H. D. Mansilla, “Optimized Photodegradation of Reactive Blue 19 on $\mathrm{TiO}_{2}$ and ZnO Suspensions," Catalysis Today, Vol. 76, 2002, pp. 235-239. doi:10.1016/S0920-5861(02)00222-5

[13] N. Daneshvar, D. Salari and A. R. Khataee, "Photocatalytic Degradation of Azo Dye Acid Red 14 in Water on $\mathrm{ZnO}$ as an Alternative Catalyst to $\mathrm{TiO}_{2}$," Journal of Photochemistry and Photobiology A: Chemistry, Vol. 162, 2004, pp. 317-322. doi:10.1016/S1010-6030(03)00378-2

[14] D. L. Liao, C. A. Badour and B. Q. Liao, "Preparation of Nano-Sized $\mathrm{TiO}_{2} / \mathrm{ZnO}$ Composite Catalyst and Its Photocatalytic Activity for Degradation of Methyl Orange," Journal of Photochemistry and Photobiology A: Chemistry, Vol. 194, 2008, pp. 11-19. doi:10.1016/jjphotochem. 2007.07.008

[15] K. Gouvea, F. Wypych, S. G. Moraes, N. Duran, N. Nagata and P. Peralta-Zamora, "Semiconductor-Assisted Photocatalytic Degradation of Reactive Dyes in Aqueous Solution," Chemosphere, Vol. 40, 2000, pp. 433-440. doi: 10.1016/S0045-6535(99)00313-6

[16] R. Y. Hong, T. T. Pan, J. Z. Qian and H. Z. Li, "Synthesis and Surface Modification of ZnO Nanoparticles," Chemical Engineering Journal, Vol. 119, 2006, pp.71-81. doi:10.1016/j.cej.2006.03.003
[17] R. Y. Hong, J. Z. Qian and J. X. Cao, "Synthesis and Characterization of PMMA Grafted ZnO Nanoparticles,” Powder Technology, Vol. 163, 2006, pp. 160-168. doi: 10.1016/j.powtec.2006.01.015

[18] R. Y. Hong, L. L. Chen, J. H. Li, H. Z. Li, Y. Zheng and J. Ding, "Preparation and Application of Polystyrene-Grafted ZnO Nanoparticles,” Polymers for Advanced Technologies, Vol. 18, No. 11, 2007, pp. 901-909. doi:10.1002/pat.926

[19] C. C. Chen, P. Liu and C. H. Lu, "Synthesis and Characterization of Nano-Sized ZnO Powders by Direct Precipitation Method," Chemical Engineering Journal, Vol. 144, 2008, pp. 509-513. doi:10.1016/j.cej.2008.07.047

[20] C. C. Chen, P. Liu, J. F. Liu and B. H. Yu, “The Investigation of Photocatalytic Activity of Nano-Sized ZnO Particles Synthesized by a Direct Precipitation Method for Degradation of Methyl Orange," (submitted to Journal of Photochemistry and Photobiology A: Chemistry).

[21] C. Chen, B. Yu, J. Liu, Q. Dai, Y. Zhu, "Investigation of ZnO Films on Si(111) Substrate Grown by Low Energy $\mathrm{O}^{+}$Assisted Pulse Laser Deposited Technology," Materials Letters, Vol. 61, 2007, pp. 2961-2964. doi:10.1016 /j.matlet.2006.10.047

[22] M. S. T. Goncalves, A. M. F. Oliveira-Campos, E. M. M. S. Pinto, P. M. S. Plasencia and M. J. R. P. Queiroz, "Photochemical Treatment of Solutions of Azo Dyes Containing $\mathrm{TiO}_{2}$," Chemosphere, Vol. 39, 1999, pp. 781-786. doi:10.1016/S0045-6535(99)00013-2

[23] W. Nam, J. Kim and G. Y. Han, "Photocatalytic Oxidation of Methul Orange in a Three-Phase Fluidized Bed Reactor," Chemosphere, Vol. 47, 2002, pp. 1019-1024. doi:10.1016/S0045-6535(01)00327-7

[24] E. Topoglidis, A. E. G. Cass, B. O’Regan and J. R. Durrant, "Immobilisation and Bioelectrochemistry of Proteins on Nanoporous $\mathrm{TiO}_{2}$ and $\mathrm{ZnO}$ Films," Journal of Electroanalytical Chemistry, Vol. 517, 2001, pp. 20-27. doi:10.1016/S0022-0728(01)00673-8

[25] A. Fujishima, T. N. Rao and D. A. Tryk, “Titanium Dioxide Photocatalysis," Journal of Photochemistry and Photobiology C: Photochemistry Reviews, Vol. 1, 2000, pp. 1-21. doi:10.1016/S1389-5567(00)00002-2

[26] A. V. Emeline, W. Ryabchuk and N. Serpone, "Factors Affecting the Efficiency of a Photocatalysed Process in Aqueous Metal-Oxide Dispersions, Prospect of Distinguishing Between Two Kinetic Models," Journal of Photobiology A: Chemistry, Vol. 133, 2000, pp. 89-97. doi:10.1016/S1010-6030(00)00225-2 